\title{
Effects on liver and serum lipids of dietary supplements of methionine and excess lysine given to previously-starved rats
}

\author{
BY YORITAKA AOYAMA, KAZUHIRO SAKAIDA, AKIRA YOSHIDA \\ AND KIYOSHI ASHIDA
}

\author{
Laboratory of Nutritional Biochemistry, Department of Agricultural Chemistry, Nagoya \\ University, Furo-cho, Chikusa, Nagoya, Japan
}

(Received 4 November 1982 - Accepted 26 May 1983)

\begin{abstract}
1. The addition of lysine hydrochloride $(50 \mathrm{~g} / \mathrm{kg}$ ) to a diet supplemented with methionine $(3 \mathrm{~g} / \mathrm{kg})$ had no effect on liver lipids when rats (Wistar and Sprague-Dawley) were fed ad lib. for $14 \mathrm{~d}$. However, refeeding a diet supplemented with methionine and excess lysine hydrochioride to previously-starved rats (Wistar) for 6,7 or $9 \mathrm{~d}$, but not 3 or $4 \mathrm{~d}$, resulted in liver lipid accumulation, mainly triglycerides, which was prevented by the addition of arginine, citrulline, ornithine, adenine, allopurinol or maize oil, but not by guanine, cytosine, thymine or uracil.

2. The addition of lysine hydrochloride to a methionine-supplemented diet resulted in reduced serum triglyceride levels after refeeding for 3 or $4 \mathrm{~d}$ and reduced serum cholesterol levels after refeeding for 3,4 or $6 \mathrm{~d}$. Serum lipids were unaffected by refeeding the diets for 7 or $9 \mathrm{~d}$.

3. Since hepatic lipid accumulation was preceded by the decline in the level of serum triglycerides, one of the factors responsible for lipid accumulation in the liver might be reduced transport of triglycerides from the liver into the blood.

4. When adenine and allopurinol were added to the diet supplemented with methionine and lysine hydrochloride refed for $4 \mathrm{~d}$, there was an increase in serum triglycerides. However, when this diet was refed for $7 \mathrm{~d}$, with the addition of arginine, citrulline, guanine, pyrimidine bases, allopurinol or maize oil, no effects on serum cholesterol and triglyceride levels were observed.
\end{abstract}

Lipid accumulation in the liver of rats induced by the addition of orotic acid to the diet was first reported by Standerfer \& Handler (1955). An arginine-deficient diet has also been shown to produce lipid accumulation in rat liver (Milner \& Perkin, 1978) and orotic aciduria is associated with arginine deficiency (Milner \& Visek, 1975; Milner, 1979). Lipid accumulation in the liver of rats receiving either an orotic acid-supplemented diet or an arginine-deficient diet was prevented by the addition of adenine, allopurinol or maize oil (Handschumacher et al. 1960; Aoyama \& Ashida, 1979; Milner, 1979; Aoyama et al. 1981). Serum triglyceride and cholesterol levels were reduced in rats given either an orotic acid-supplemented diet or an arginine-deficient diet (Windmueller \& Spaeth, 1966; Milner, 1979; Aoyama et al. 1981).

Hevia \& Visek (1980) and Hevia et al. $(1980 a, b)$ found that the addition of an excess amount of lysine to a diet containing $150 \mathrm{~g}$ casein $/ \mathrm{kg}$ and supplemented with $3 \mathrm{~g}$ methionine $/ \mathrm{kg}$ resulted in lipid accumulation in the liver. This is similar to the lipid accumulation in the liver of rats given either an orotic acid-supplemented diet or an arginine-deficient diet. In fact, Ulman et al. (1981) reported orotic aciduria caused by feeding excess lysine to growing rats. However, serum triglyceride and cholesterol levels were not depressed in rats given a diet containing $(\mathrm{g} / \mathrm{kg}): 150$ casein, 3 methionine, 50 lysine hydrochloride (Hevia \& Visek, 1980; Hevia et al. 1980a, b). The response of serum lipids to feeding the diet containing excess lysine was not similar to that observed in rats given either an orotic acid-supplemented diet or an arginine-deficient diet. The present study was designed to determine the effects of various additions to a diet supplemented with excess lysine on the accumulation of lipids in the liver and serum of rats. 
Table 1. Composition of the diets

\begin{tabular}{|c|c|c|c|}
\hline $\begin{array}{l}\text { Diet... } \\
\text { Ingredients }\end{array}$ & $\begin{array}{l}\text { Fed before } \\
\text { the beginning } \\
\text { of experiment } \\
\text { (control) }\end{array}$ & $\begin{array}{l}\text { Supplemented } \\
\text { with methionine } \\
\text { (Met) }\end{array}$ & $\begin{array}{l}\text { Supplemented } \\
\text { with methionine } \\
\text { and lysine } \\
\text { hydrochloride } \\
\text { (Met + Lys) }\end{array}$ \\
\hline Casein $(\mathrm{g} / \mathrm{kg})^{*}$ & 150 & 150 & 150 \\
\hline L-Methionine $(\mathrm{g} / \mathrm{kg}) \dagger$ & - & 3 & 3 \\
\hline $\mathrm{L}$-Lysine hydrochloride $(\mathrm{g} / \mathrm{kg}) \dagger$ & - & - & 50 \\
\hline Mineral mixture $(\mathrm{g} / \mathrm{kg})_{\ddagger}^{\ddagger}$ & 40 & 40 & 40 \\
\hline Vitamin mixture $(\mathrm{g} / \mathrm{kg}) \ddagger$ & $8 \cdot 5$ & 8.5 & 8.5 \\
\hline Choline chloride $(\mathrm{g} / \mathrm{kg})^{*}$ & 1.5 & $1 \cdot 5$ & $1 \cdot 5$ \\
\hline Maize oil $(\mathrm{g} / \mathrm{kg}) \S$ & 20 & 20 & 20 \\
\hline Sucrose $\|$ or $\alpha$-starch $(\mathrm{g} / \mathrm{kg})$ & 780 & 777 & 727 \\
\hline Retinyl palmitate $(\mathrm{mg} / \mathrm{kg})^{* *}$ & 4 & 4 & 4 \\
\hline Ergocalciferol $(\mu \mathrm{g} / \mathrm{kg})^{* *}$ & 15 & 15 & 15 \\
\hline DL- $\alpha$-Tocopheryl acetate $(\mathrm{mg} / \mathrm{kg})^{* *}$ & 100 & 100 & 100 \\
\hline
\end{tabular}

* Katayama Chemical Industries Co. Ltd, Osaka, Japan.

$\dagger$ Ajinomoto Co. Inc., Tokyo, Japan.

$\ddagger$ For details, see Aoyama et al. (1971).

$\S$ Nihon Syokuhin Kako Co. Ltd, Fuji, Shizuoka, Japan.

$\|$ For Expts 1 and 2.

- Potato; Chuo Food Co. Ltd, Inazawa, Aichi, Japan. For Expts 3-7.

** Eisai Co. Ltd, Tokyo, Japan.

\section{METHODS}

Male rats (Shizuoka Agricultural Cooperative Association for Laboratory Animals) of the Wistar (Expts 1, 3-7) or Sprague-Dawley (Expt 2) strain were housed individually in screen-bottom cages in an air-conditioned room at a temperature of approximately $23^{\circ}$. Light was regulated to provide equal periods of light (08.00-20.00 hours) and dark (20.00-08.00 hours). The compositions of the experimental diets are shown in Table 1. Free access to food was available except during starvation. Water was given ad lib. throughout the experimental periods. Before beginning the periods of feeding (Expts 1 and 2), or starvation for $3 \mathrm{~d}$ (Expts 3-7), rats were given a diet containing $150 \mathrm{~g}$ casein $/ \mathrm{kg}$ with sucrose (Expts 1 and 2) or $\alpha$-starch (potato) (Expts 3-7) as the carbohydrate source for 3-5 d.

Expts 1 and 2. Rats of the Wistar (Expt 1) or Sprague-Dawley (Expt 2) strain were given a diet supplemented with methionine alone or methionine and lysine hydrochloride for 0 or $14 \mathrm{~d}$ without previous starvation.

Expt 3. Rats previously starved for $3 \mathrm{~d}$ were refed a diet supplemented with methionine alone or methionine and lysine hydrochloride for $0,3,6$ or $9 \mathrm{~d}$.

Expt 4. Rats previously starved for $3 \mathrm{~d}$ were refed a diet supplemented with methionine alone, methionine and lysine hydrochloride or methionine, lysine hydrochloride and urea-cycle intermediates $(10 \mathrm{~g} / \mathrm{kg}$; L-arginine, L-citrulline or L-ornithine hydrochloride) for $7 \mathrm{~d}$.

Expt 5. Rats previously starved for $3 \mathrm{~d}$ were refed a diet supplemented with methionine and lysine hydrochloride or a diet supplemented with methionine, lysine hydrochloride and purine or pyrimidine bases $(2 \mathrm{~g} / \mathrm{kg}$; adenine, guanine, cytosine, thymine or uracil) for $7 \mathrm{~d}$.

Expt 6. Rats previously starved for $3 \mathrm{~d}$ were refed a diet supplemented with methionine alone, methionine and lysine hydrochloride or methionine, lysine hydrochloride and adenine $(1 \mathrm{~g} / \mathrm{kg})$, allopurinol $(1 \mathrm{~g} / \mathrm{kg})$ or maize oil $(130 \mathrm{~g} / \mathrm{kg})$ for $4 \mathrm{~d}$.

Expt 7. Rats previously starved for $3 \mathrm{~d}$ were refed a diet supplemented with methionine 
Table 2. Expts 1 and 2. Body-weight gain, liver weight and liver lipid content of rats given either a diet supplemented with methionine alone (Met) or a diet supplemented with methionine and lysine hydrochloride (Met + Lys)

(Mean values for five rats per group)

\begin{tabular}{|c|c|c|c|c|c|c|c|}
\hline Strain & Diet & $\begin{array}{l}\text { Feeding } \\
\text { periods } \\
\text { (d) }\end{array}$ & $\begin{array}{c}\text { Initial } \\
\text { body-wt } \\
\text { (g) }\end{array}$ & $\begin{array}{c}\text { Food } \\
\text { intake } \\
(\mathrm{g} / 14 \mathrm{~d})\end{array}$ & $\begin{array}{c}\text { Body-wt } \\
\text { gain } \\
(\mathrm{g} / 14 \mathrm{~d})\end{array}$ & $\begin{array}{c}\text { Liver } \\
\text { wt } \\
\text { (g/kg body-wt) }\end{array}$ & $\begin{array}{c}\text { Liver } \\
\text { lipids } \\
\text { (mg/g liver) }\end{array}$ \\
\hline \multicolumn{8}{|c|}{ Experiment 1} \\
\hline Wistar & Control & 0 & $75 \cdot 4$ & - & - & $45 \cdot 5^{b}$ & $57 \cdot 0^{a}$ \\
\hline Wistar & Met & 14 & $75 \cdot 4$ & $158^{a}$ & $59 \cdot 6^{a}$ & $50 \cdot 5^{b}$ & $53 \cdot 5^{a}$ \\
\hline \multirow[t]{2}{*}{ Wistar } & Met + Lys & 14 & $75 \cdot 4$ & $141^{a}$ & $35 \cdot 6^{b}$ & $56 \cdot 2^{a}$ & $49 \cdot 5^{a}$ \\
\hline & Pooled SEM & & $2 \cdot 1$ & 6 & $2 \cdot 6$ & $1 \cdot 7$ & $2 \cdot 7$ \\
\hline \multicolumn{8}{|c|}{ Experiment 2} \\
\hline SD & Control & 0 & $71 \cdot 4$ & - & - & $56 \cdot 2^{a}$ & $56 \cdot 6^{a}$ \\
\hline SD & Met & 14 & $71 \cdot 4$ & $178^{a}$ & $87 \cdot 2^{a}$ & $55.7^{a}$ & $70 \cdot 7^{a}$ \\
\hline \multirow[t]{2}{*}{ SD } & Met + Lys & 14 & $71 \cdot 2$ & $134^{b}$ & $45 \cdot 6^{b}$ & $55 \cdot 1^{a}$ & $53 \cdot 6^{a}$ \\
\hline & Pooled SEM & & $2 \cdot 1$ & 8 & 4.2 & $2 \cdot 0$ & 8.5 \\
\hline
\end{tabular}

${ }^{a, b}$ In each experiment, means within the same vertical column that do not share a common superscript letter were significantly different: $P<0 \cdot 05$. SD, Sprague-Dawley.

and lysine hydrochloride alone or methionine, lysine hydrochloride and adenine $(1 \mathrm{~g} / \mathrm{kg})$, allopurinol $(1 \mathrm{~g} / \mathrm{kg})$ or maize oil $(55$ or $130 \mathrm{~g} / \mathrm{kg})$ for $7 \mathrm{~d}$.

Changes in dietary levels of methionine $(3 \mathrm{~g} / \mathrm{kg})$, lysine hydrochloride $(50 \mathrm{~g} / \mathrm{kg})$, arginine $(10 \mathrm{~g} / \mathrm{kg})$, citrulline $(10 \mathrm{~g} / \mathrm{kg})$, ornithine hydrochloride $(10 \mathrm{~g} / \mathrm{kg})$, adenine $(1$ or $2 \mathrm{~g} / \mathrm{kg})$, guanine $(2 \mathrm{~g} / \mathrm{kg})$, cytosine $(2 \mathrm{~g} / \mathrm{kg})$, thymine $(2 \mathrm{~g} / \mathrm{kg})$, uracil $(2 \mathrm{~g} / \mathrm{kg})$, allopurinol $(1 \mathrm{~g} / \mathrm{kg})$ and maize oil $(55$ or $130 \mathrm{~g} / \mathrm{kg})$ were compensated for by adjusting the amounts of carbohydrates.

At the end of the experimental periods ( 0 and $14 \mathrm{~d}$ for Expts 1 and 2; 0, 3, 6 and $9 \mathrm{~d}$ for Expt 3; $7 \mathrm{~d}$ for Expts 4, 5 and 7 and $4 \mathrm{~d}$ for Expt 6), diets were withheld at 09.00 hours. Blood was removed from the hearts of rats which had been anaesthetized with diethyl ether between 15.30-16.30 hours after fasting for $7 \mathrm{~h}$. Livers were immediately excised and weighed. Total lipids were extracted and purified by the method of Folch et al. (1957). Lipids soluble in chloroform-methanol $(2: 1, \mathrm{v} / \mathrm{v})$ were used for the determination of phospholipids (assumed to be the amount of phosphorus $\times 25$ ) (Barlet, 1959) and total cholesterol (free and esterified) (Pearson et al. 1953). Triglycerides were estimated by difference (total lipids minus phospholipids and cholesterol).

Triglycerides and total cholesterol in serum were determined by the methods of Wahlefeld (1974) and Pearson et al. (1953) respectively.

All values were subjected to analysis of variance and Duncan's multiple-range test (Duncan, 1955) to determine whether differences in means were significant $(P<0.05)$.

\section{RESULTS}

Expts 1 and 2

The effects on food intake, body-weight gain, liver weight and liver lipids of feeding a diet supplemented with methionine alone or methionine and lysine hydrochloride for $14 \mathrm{~d}$ to rats not previously starved are shown in Table 2 . The amount of food consumed by rats given a diet supplemented with methionine alone tended to be greater than that of rats fed an unsupplemented diet or the same diet supplemented with lysine hydrochloride (the increase was significant only for the Sprague-Dawley rats). Body-weight gain of both strains 


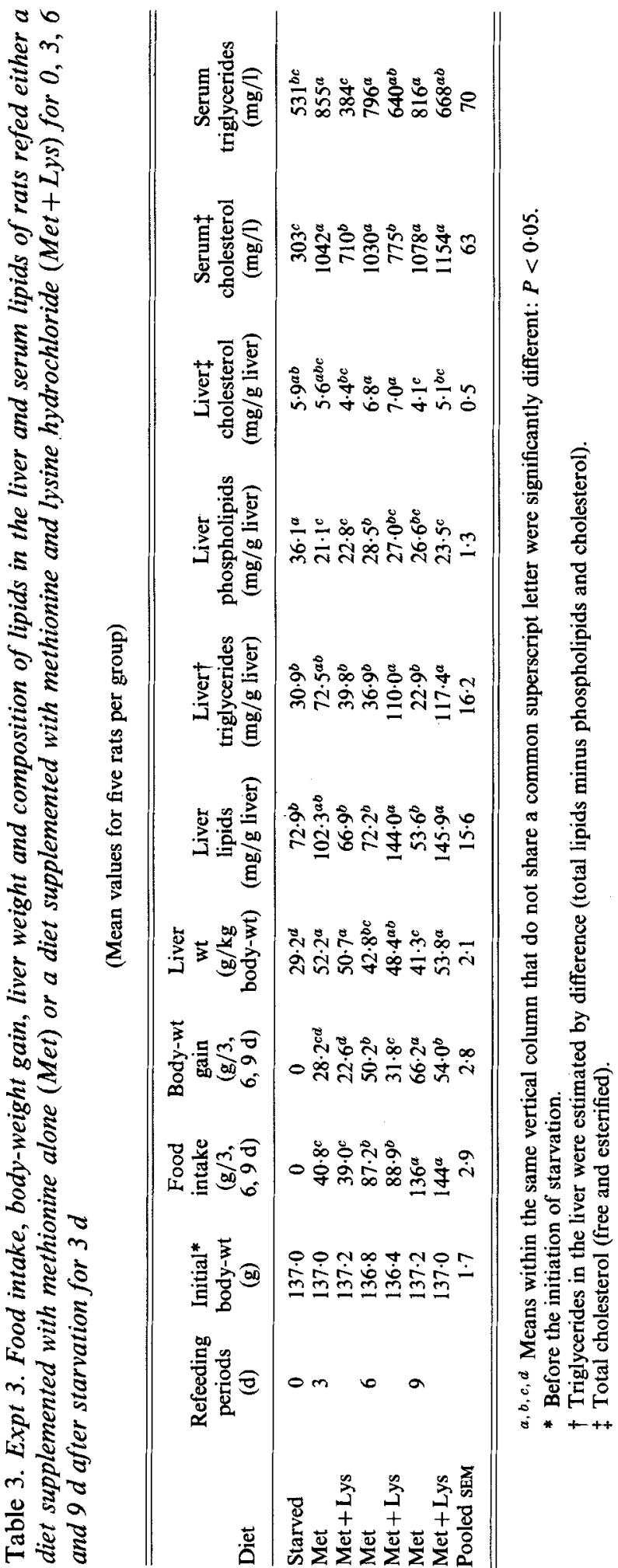


of rats was significantly larger in rats given the methionine-supplemented diet compared with rats given the diet supplemented with methionine and lysine hydrochloride. Liver weight increased when the supplementary methionine and lysine hydrochloride diet was given to Wistar rats whereas, in the Sprague-Dawley strain, liver weight was unaffected by dietary supplementation. Liver lipid contents of both strains of rats were unaffected by dietary supplementation.

\section{Expt 3}

The effects of refeeding a diet supplemented with methionine alone or methionine and lysine hydrochloride for $0,3,6$ or $9 \mathrm{~d}$ are shown in Table 3 . The presence of lysine hydrochloride did not affect food intake, but tended to reduce body-weight gain over $3 \mathrm{~d}$ and this was significant after 6 and $9 \mathrm{~d}(P<0 \cdot 05)$. Livers of rats given methionine and lysine hydrochloride supplements for $9 \mathrm{~d}$ were heavier than those of rats given supplementary methionine only. When rats were refed the diet with methionine and lysine hydrochloride for 6 or $9 \mathrm{~d}$, liver lipid and triglyceride contents increased. Levels of phospholipids in the liver decreased after refeeding but the values of phospholipids and cholesterol were generally unaffected by the type of dietary supplementation. Serum triglyceride levels in rats refed a diet with methionine and lysine hydrochloride for $3 \mathrm{~d}$ were significantly lower than those in rats refed a diet with methionine alone for $3 \mathrm{~d}$. Cholesterol values in serum of rats refed a diet with methionine and lysine hydrochloride for 3 or $6 \mathrm{~d}$ were significantly lower than those of rats refed a diet with methionine alone for 3 or $6 \mathrm{~d}$ respectively, while refeeding for $9 \mathrm{~d}$ had no effects on serum cholesterol and triglycerides.

\section{Expt 4}

The effects on food intake, body-weight gain, liver weight, liver lipids, serum cholesterol and triglyceride levels of adding urea-cycle intermediates to a diet supplemented with methionine and lysine hydrochloride are shown in Table 4. The addition of arginine, citrulline or ornithine hydrochloride had no effect on food consumption. Body-weight gain of rats given the diet supplemented with methionine and lysine hydrochloride was smaller than that of rats given the diet supplemented with methionine alone. The addition of arginine or citrulline, but not ornithine hydrochloride, to the diet supplemented with methionine and lysine hydrochloride caused a significant increase in body-weight gain. Liver weight and liver lipid concentration of rats given methionine and lysine hydrochloride supplements were larger than the corresponding values for rats given methionine alone, which were similar to those observed when urea-cycle intermediates were added. The addition of urea-cycle intermediates had no effect on serum cholesterol and triglyceride concentrations, with the exception of serum triglycerides in rats receiving ornithine hydrochloride.

\section{Expt 5}

The effects of purine and pyrimidine bases are shown in Table 4. The addition of adenine, but not of guanine, cytosine, thymine or uracil to a diet supplemented with methionine and lysine hydrochloride resulted in decreased food consumption, body-weight gain, liver weight and liver lipid concentration. Serum cholesterol levels of rats given supplementary methionine and lysine hydrochloride were similar to those of rats receiving the same diet supplemented with purine or pyrimidine bases. Serum triglyceride levels of rats given adenine were higher than those of the other groups which had similar levels.

\section{Expts 6 and 7}

The effects of dietary adenine, allopurinol and maize oil on rats refed a diet supplemented with methionine and lysine hydrochloride for 4 or $7 \mathrm{~d}$ are shown in Table 5 . When rats 


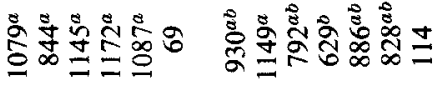

章

ล

ปั

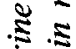

:

艾

à

किष

$+\infty$

$\stackrel{5}{\infty}$

so

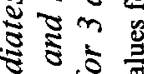

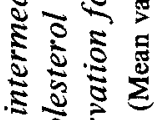

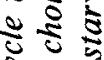

ปั้

$\sin$

इ.

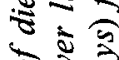

จ.

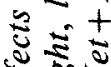

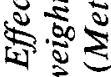

in:

จิ

s.

商

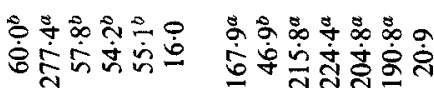

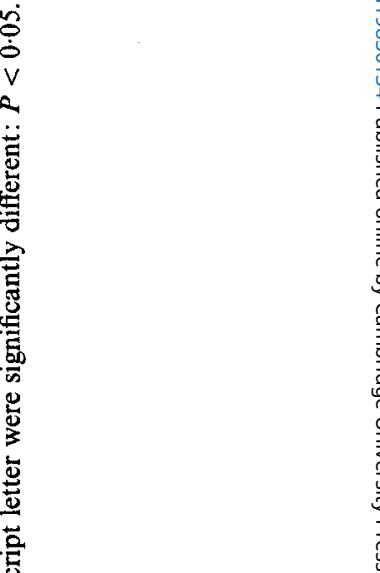

$\rightarrow \cdot 5$

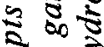

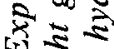

मी.

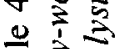

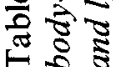

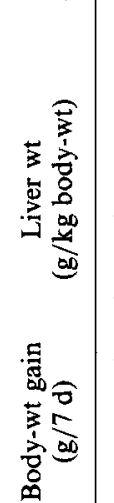

웅 웅우

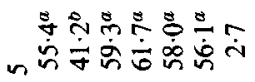

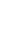

崖

\& 8 :

$$
\text { 氞 }
$$

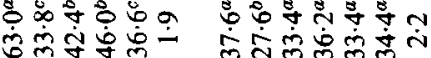

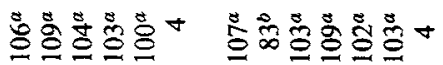

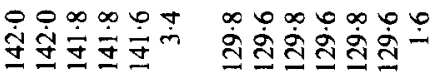


Excess lysine and liver lipids

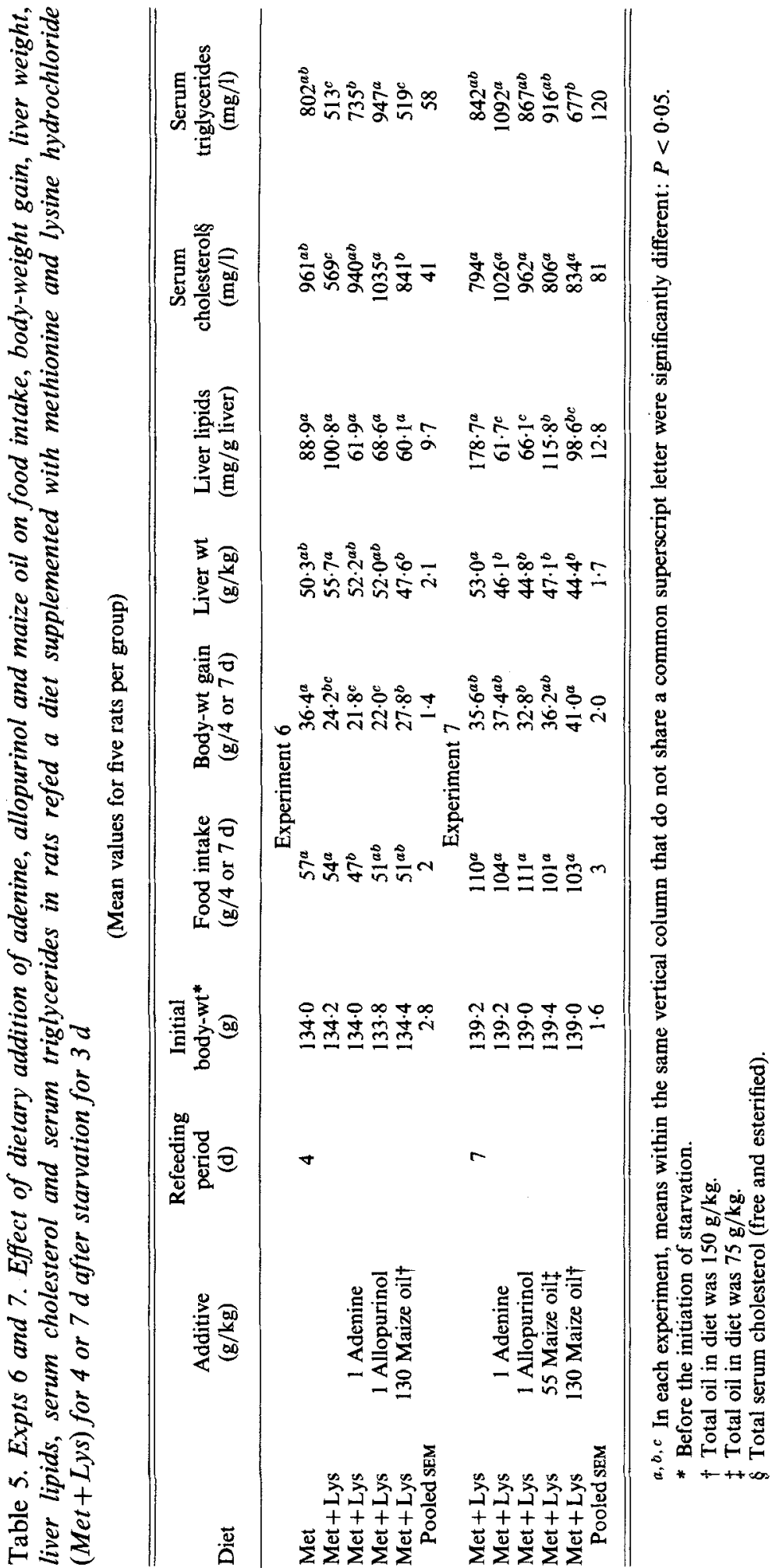


were refed for $4 \mathrm{~d}$ there were no changes in food intake and liver lipids. Body-weight gain after $4 \mathrm{~d}$ of refeeding was decreased by the presence of lysine hydrochloride. The addition of maize oil ( $150 \mathrm{~g}$ total maize oil $/ \mathrm{kg}$ diet) decreased liver weight. Both serum cholesterol and triglyceride levels in rats receiving methionine alone were significantly higher than those of rats given the diet supplemented with methionine and lysine hydrochloride. The addition of adenine or allopurinol to the latter diet resulted in an increase in serum cholesterol and triglyceride levels, whereas the addition of maize oil resulted in an increase in serum cholesterol but not in serum triglycerides.

When rats were refed for $7 \mathrm{~d}$, the addition of adenine, allopurinol or maize oil ( $75 \mathrm{~g}$ or $150 \mathrm{~g}$ total maize oil $/ \mathrm{kg}$ diet) had no effect on food intake, body-weight gain, serum cholesterol or serum triglycerides but resulted in a decrease in liver weight and liver lipid concentration.

\section{DISCUSSION}

Hevia \& Visek (1980) and Hevia et al. $(1980 a, b)$ reported lipid accumulation in the liver of rats given a diet supplemented with methionine and lysine hydrochloride for 2 weeks. As shown in Table 2, rats of the Wistar strain did not develop fatty livers when given a diet supplemented with methionine and lysine hydrochloride (Expt 1). Since the previouslymentioned authors used Sprague-Dawley rats to demonstrate the development of fatty liver by adding excess lysine to a methionine-supplemented diet, we also used Sprague-Dawley rats to study the effects of the experimental diets on liver lipid content. There were no significant changes in liver lipids (Table 2).

Refeeding a diet supplemented with methionine and lysine hydrochloride for $3 \mathrm{~d}$ to previously-starved rats did not result in lipid accumulation in the liver (Expt 3, Table 3), whereas refeeding for 6 or $9 \mathrm{~d}$ resulted in liver lipid accumulation. The increase in lipid accumulation in the liver of rats refed a diet supplemented with methionine and lysine hydrochloride was assumed to be mainly due to triglycerides. Liver lipids include diglycerides and free fatty acids as well as triglycerides, phospholipids and cholesterol. The concentrations of diglycerides and free fatty acids in the liver lipids were less than 2 and $4 \mathrm{~g} / \mathrm{kg}$ lipids respectively (Creasey et al. 1961; Ugazio \& Lombardi, 1965) so, although these lipids were included in the triglyceride fraction, they are minor components. The increase in triglycerides in the liver is a common feature when rats develop fatty liver (Creasey et al. 1961; Ugazio \& Lombardi, 1965; Lombardi et al. 1966; Aoyama et al. 1975). Therefore, a study was made of the effects of various dietary additives on liver lipids of rats after refeeding for $7 \mathrm{~d}$.

Hevia \& Visek (1980) reported that lipid accumulation in the liver of rats refed a diet supplemented with methione and lysine hydrochloride was prevented by the addition of arginine. A similar effect was observed with both citrulline and ornithine (Expt 4, Table 4). Therefore, it is possible that the addition of excess lysine caused an arginine deficiency.

Of the purine and pyrimidine bases only adenine was effective in preventing lipid accumulation in the liver (Expts 5 and 7, Tables 4 and 5). This response might be similar to that obtained when adenine was added to either an orotic acid-supplemented diet (Handschumacher et al. 1960) or an arginine-deficient diet (Aoyama \& Ashida, 1979; Milner, 1979; Aoyama et al. 1981). The addition of adenine to a diet supplemented with methionine and lysine hydrochloride resulted in lowered food consumption and body-weight gain (Expt 5, Table 4). While no significant effects on food consumption and body-weight gain by adding adenine were observed (Expt 7, Table 5), this might be due to the different amounts of adenine added $(2 \mathrm{~g} / \mathrm{kg}$ in Expt 5 and $1 \mathrm{~g} / \mathrm{kg}$ in Expt 7$)$ to the diet supplemented with methionine and lysine hydrochloride.

Allopurinol was also effective in preventing lipid accumulation in the liver of rats refed 
a diet supplemented with methionine and lysine hydrochloride (Expt 7, Table 5). A similar response was obtained when allopurinol was added to an orotic acid-supplemented diet (Windmueller \& von Euler, 1971; Aoyama et al. 1981) or an arginine-devoid diet (Aoyama et al. 1981). As allopurinol is an inhibitor of xanthine oxidase (Feigelson et al. 1957), degradation of purine bases would be depressed. Thus, the concentrations of adenine, AMP, ADP or ATP in the liver might not decline and the effects would be similar to those seen when adenine was added to the diet. Allopurinol, and oxypurinol formed from allopurinol, can be metabolized to their respective ribonucleotides which may inhibit the step of pyrimidine biosynthesis involving orotidylic acid decarboxylase (EC 4.1.1.23) (Fyfe et al. 1974). Therefore, it is possible that an abnormality in purine and pyrimidine metabolism in rats given an orotic acid-supplemented diet, an arginine-deficient diet or a diet supplemented with methionine and lysine hydrochloride caused lipid accumulation in the liver.

Maize oil added to a diet supplemented with methionine and lysine hydrochloride was found to prevent lipid accumulation in the liver (Expt 7). A similar response was obtained when safflower oil was added to an arginine-deficient diet or an orotic acid-supplemented diet (Aoyama et al. 1981). It has been reported that, when a high-carbohydrate, low-fat diet supplemented with a high level of linoleic acid oil is fed to rats, there is a progressive suppression of both lipogenesis and the activities of liver enzymes which participate in the synthesis of saturated and mono-unsaturated fatty acids (Sabine et al. 1969; Muto \& Gibson, 1970). Therefore, it would appear that the presence of polyunsaturated fatty acids in the diet might be of major importance in the inhibition of hepatic fatty acid synthesis. Thus, since liver lipid accumulation induced by refeeding an arginine-deficient diet or an orotic acid-supplemented diet was effectively inhibited by the addition of safflower oil, it seems reasonable to conclude that the formation of fatty liver under our experimental conditions might be in part due to enhanced fatty acid synthesis in the liver.

Hevia et al. $(1980 a, b)$ found that lipid accumulation in the livers of rats given a diet supplemented with methionine and lysine hydrochloride was not associated with changes in serum lipid concentration. Similarly, no significant changes were observed in either serum cholesterol or serum triglyceride levels when diets supplemented with methionine alone or methionine and lysine hydrochloride were refed for 7 or $9 \mathrm{~d}$ (Expts 3 and 4). These results are not identical to those that show that lipid accumulation in the liver induced by refeeding an arginine-deficient diet (Milner, 1979; Aoyama et al. 1981) or an orotic acid-supplemented diet (Windmueller \& Spaeth, 1966) are the result of a major block in triglyceride transport from liver into blood. However, serum triglycerides in rats refed a diet supplemented with methionine and lysine hydrochloride for 3 or $4 \mathrm{~d}$ were significantly lower than those in rats receiving the methionine-supplemented diet alone (Expts 3 and 6). When these experimental diets were refed for 6 (Expt 3) or $7 \mathrm{~d}$ (Expt 4) a similar tendency was obtained. Lipid accumulation in the liver occurred after refeeding for $6 \mathrm{~d}$ (Expt 3 ). These findings show that a reduction in serum triglyceride levels preceded liver lipid accumulation. Therefore, the observed decline in triglyceride transport from the liver might be responsible for the lipid accumulation in the liver when rats were refed a diet supplemented with methionine and lysine hydrochloride.

When adenine or allopurinol was added to a diet supplemented with methionine and lysine hydrochloride, there was an increase in the level of serum triglycerides (Expt 6). Similarly, Milner (1979) and Aoyama et al. (1981) reported that the addition of adenine or allopurinol to an arginine-deficient diet resulted in increased serum triglyceride levels. When lipid accumulation in the liver was prevented by the addition of adenine or allopurinol, the serum triglyceride levels returned to those found in rats refed a diet supplemented with methionine and lysine hydrochloride (Expt 7). 
The addition of maize oil to a diet supplemented with methionine and lysine hydrochloride had no effect on serum triglyceride levels (Expt 6). This might be due to the decreased synthesis of lipids in the liver.

\section{REFERENCES}

Aoyama, Y. \& Ashida, K. (1979). Nutrition Reports International 20, 483-490.

Aoyama, Y., Izumichi, T., Sakakibara, H., Yoshida, A. \& Ashida, K. (1975). Nutrition Reports International 12, $163-173$.

Aoyama, Y., Yasui, H. \& Ashida, K. (1971). Journal of Nutrition 101, 739-745.

Aoyama, Y., Yoshida, A. \& Ashida, K. (1981). Journal of Nutrition 111, 895-906.

Barlet, G. R. (1959). Journal of Biological Chemistry 234, 466-468.

Creasey, W. A., Hankin, L. \& Handschumacher, R. E. (1961). Journal of Biological Chemistry 236, $2064-2070$.

Duncan, D. B. (1955). Biometrics 11, 1-42.

Feigelson, P., Davidson, J. D. \& Robins, R. K. (1957). Journal of Biological Chemistry 226, 993-1000.

Folch, J., Lees, M. \& Sloane Stanley, G. H. (1957). Journal of Biological Chemistry 226, 497-509.

Fyfe, J. A., Nelson, D. J. \& Hitching, G. H. (1974). Advances in Experimental Medicine and Biology 41 B, $621-628$.

Handschumacher, R. E., Creasey, W. A., Jaffe, J. J., Pasternak, C. A. \& Hankin, L. (1960). Proceedings of the National Academy of Sciences of the USA 36, 178-186.

Hevia, P., Kari, F. W., Ulman, E. A. \& Visek, W. J. (1980a). Journal of Nutrition 110, 1224-1230.

Hevia, P., Ulman, E. A., Kari, F. W. \& Visek, W. J. (1980b). Journal of Nutrition 110, 1231-1239.

Hevia, P. \& Visek, W. J. (1980). Lipids 15, 95-99.

Lombardi, B., Ugazio, G. \& Raick, A. (1966). American Journal of Physiology 210, 31-36.

Milner, J. A. (1979). Journal of Nutrition 109, 663-670.

Milner, J. A. \& Perkin, E. G. (1978). Lipids 13, 563-565.

Milner, J. A. \& Visek, W. J. (1975). Metabolism 24, 643-651.

Muto, Y. \& Gibson, D. M. (1970). Biochemical and Biophysical Research Communications 38, 9-15.

Pearson, S., Stern, S. \& McGavack, T. H. (1953). Analytical Chemistry 25, 813-814.

Sabine, J. R., McGrath, H. \& Abraham, S. (1969). Journal of Nutrition 98, 312-318.

Standerfer, S. B. \& Handler, P. (1955). Proceedings of the Society for Experimental Biology and Medicine 90, $270-271$. Ugazio, G. \& Lombardi, B. (1965). Laboratory Investigation 14, 711-719.

Uiman, E. A., Kari, F. W., Hevia, P. \& Visek, W. (1981). Journal of Nutrition 111, 1772-1779.

Wahlefeld, A. W. (1974). Methods of Enzymatic Analysis 4, 1831-1835.

Windmueller, H. G. \& Spaeth, A. E. (1966). Journal of Biological Chemistry 241, 2891-2899.

Windmueller, H. G. \& von Euler, L. H. (1971). Proceedings of the Society for Experimental Biology and Medicine 136, 98-101. 